\title{
Understanding technology mediation and new service provider roles in healthcare
}

DOI:

10.1108/jsm-11-2017-0368

\section{Document Version}

Accepted author manuscript

Link to publication record in Manchester Research Explorer

\section{Citation for published version (APA):}

Daskalopoulou, A., Keeling, K., \& Pritchard Jones, R. (2019). Understanding technology mediation and new service provider roles in healthcare. Journal of Services Marketing. https://doi.org/10.1108/jsm-11-2017-0368

\section{Published in:}

Journal of Services Marketing

\section{Citing this paper}

Please note that where the full-text provided on Manchester Research Explorer is the Author Accepted Manuscript or Proof version this may differ from the final Published version. If citing, it is advised that you check and use the publisher's definitive version.

\section{General rights}

Copyright and moral rights for the publications made accessible in the Research Explorer are retained by the authors and/or other copyright owners and it is a condition of accessing publications that users recognise and abide by the legal requirements associated with these rights.

\section{Takedown policy}

If you believe that this document breaches copyright please refer to the University of Manchester's Takedown Procedures [http://man.ac.uk/04Y6Bo] or contact uml.scholarlycommunications@manchester.ac.uk providing relevant details, so we can investigate your claim.

\section{OPEN ACCESS}




\section{Journal of Services Mar}

\section{Understanding technology mediation and new service provider roles in healthcare}

\begin{tabular}{|r|l|}
\hline Journal: & Journal of Services Marketing \\
\hline Manuscript ID & JSM-11-2017-0368.R2 \\
\hline Manuscript Type: & Article \\
\hline Keywords: & $\begin{array}{l}\text { service providers, role enactment, technology mediation, services } \\
\text { marketing }\end{array}$ \\
\hline \multicolumn{2}{|l}{} \\
\hline
\end{tabular}

\section{SCHOLARONE \\ Manuscripts}




\title{
Understanding technology mediation and new service provider roles in healthcare
}

\begin{abstract}
Purpose: Service research holds that as services become more technology dominated, new service provider roles emerge. On a conceptual level, the potential impact of different roles has been discussed in regards to service provider readiness, job performance and overall experience. However, as yet there is sparse empirical support for these conceptual interpretations. The aim of this paper is to provide an understanding of the new service provider roles that emerge due to the increase of technology mediation in services.

Methodology: This study follows a qualitative methodology. Insights are drawn from indepth interviews with thirty-two junior and senior healthcare service providers (across twelve specialties), and five information governance/management staff.

Findings: Our analysis illustrates that new service provider roles include those of the enabler, differentiator, innovator, coordinator and sense-giver. By adopting these roles, healthcare service providers reveal that they can encourage, support and advance technology mediation in services across different groups/audiences within their organizations (e.g., service delivery level, peer-to-peer level, organizational level). This paper further shows the relationships between these new service provider roles.

Originality/value: This study contributes to theory in technology-mediated services by illustrating empirically the range of activities that constitute each role. It also complements prior work by identifying that service providers adopt the additional role of sense-giver. Finally, this paper provides an understanding of how by taking on these roles service providers can encourage, support and advance technology mediation in services across different groups/audiences in their organization.
\end{abstract}

Keywords: service providers; role enactment; technology mediation; services marketing 


\section{Understanding technology mediation and new service provider roles in healthcare}

\section{Introduction}

The traditional service encounter is fundamentally changing (Bitner, Brown and Meuter, 2000; Fisk et al., 2018; Schumann, Wünderlich and Wangenhe, 2012). With the infusion of technology, services have become more dynamic and new ways of delivering services have emerged, e.g., the provision of separated services (e.g. Green, Hartley and Gillespie, 2016; Keh and Pang, 2013). The way that service providers interact with consumers has also seen a profound transformation. For example, the rise of self-service technologies has replaced in many instances dyadic service encounters between providers and consumers (e.g., Blut, Wang and Schoefer, 2016; Glushko and Nomorosa, 2012).

As services become more dynamic, organizations are trying to understand how to seamlessly integrate technology with positive service encounters (Giebelhausen et al., 2014). A number of studies have generated valuable insights about the role of technology mediation in shaping different elements of services. Mostly, this work deals with evaluations of service outcomes, such as satisfaction, uptake and consumer experience, primarily from a consumer perspective (e.g., Chowdhury et al., 2014; Makarem, Mudambi and Podoshen, 2009;

Newman, Wachter and White, 2018). Apart from a few exceptions (e.g., Green et al., 2016; Wünderlich, Wangenheim and Bitner, 2013), the service provider perspective is less represented in the literature. In essence, previous work highlights how service providers can influence the technology-mediated service in a positive way by addressing barriers associated with technology use. For example, Gallan et al. (2013) hold that it is vital for service providers to be able to recognize consumers' affective states throughout their service journey in order to enhance satisfaction and participation. To meet the requirements of service delivery, as it becomes more technology dominated, new service provider roles will emerge 
(e.g., Bowen, 2016; Larivière et al., 2017). This argument has been unpacked on a conceptual level in relation to the effects of taking up new roles for service providers, such as changes in job performance and overall service provider experience (Larivière et al. (2017). However, as yet there is sparse empirical support for these conceptual interpretations.

The aim of this study is to provide an understanding of the new service provider roles that emerge due to the increase of technology mediation in services. We draw from a qualitative study with healthcare service providers sharing their experiences of discretionary technology use, such as the use of mobile applications (apps). Specifically, we explore the interrelationship between technology use and new service provider roles. In doing so, we extend prior studies in three important ways. First, we illustrate empirically the range of activities that constitute each one of the roles previously conceptualized in the literature (e.g., Bowen, 2016; Larivière et al., 2017) and identify relationships between these roles. Second, we identify one additional service provider role. Third, we illustrate how by taking on new roles service providers can encourage, support and advance technology mediation in services across different groups or audiences in their organization (e.g., service delivery level, peer-topeer level, organizational level).

In the rest of this paper we first provide an overview of the conceptual underpinnings of role enactment, we then discuss more specifically the new roles of service providers in technology mediated services. We continue with an outline of the methods followed in this study. Our findings are presented next, followed by a discussion of our theoretical and practical implications in our concluding section. 


\section{Literature review}

\section{Role enactment}

Role theory is used to understand service interactions as social exchanges. It holds that services follow specific patterns due to the adoption of explicit roles by service providers and consumers. Service interactions can therefore be described as "role performances" (Solomon et al., 1985, p. 101) in which a pre-defined and expected set of behaviors is enacted. Accordingly, service providers and consumers adopt certain roles and have associated role expectations in the context of a service interaction (Biddle, 1986). Roles are in a sense complementary because they are defined in relation to other roles, e.g., the doctor-patient roles are mutually constitutive (Hubbert, Garcia Sehorn and Brown, 1996).

According to role theory, the predictability and familiarity of well-defined roles is a prerequisite for positive service outcomes (Solomon et al., 1985; Surprenant and Solomon, 1975). When service providers and consumers have a common understanding of role expectations, it is more likely to evaluate in a similar way their service interaction (Mohr and Bitner, 1991). On the contrary, differences in perspective can arise when roles are less defined or when someone is unfamiliar with expected behaviors (Bitner, Booms and Mohr, 1994). For example, Schau, Dellande and Gilly (2007) find that if service providers suddenly change the dialect and brand code in a service interaction it can have negative consequences. Similarly, Giebelhausen et al. (2014) reveal that if an expected element of a service interaction is violated consumers are likely to experience feelings of psychological discomfort. As such, the success or failure of a service interaction in part depends on the ‘mastery' of role behaviors (Broderick, 1998).

A need for a more advanced understanding of new service provider roles induced by the increase of technology mediation in services is thus well justified for two reasons. First, it 
is important to clarify new roles because consumers' expectations of how the provider is going to behave need to be met in order to avoid role discrepancy (Broderick, 1998). Not meeting expectations can easily lead to consumer uncertainty and dissatisfaction (Schau et al., 2007). Second, a common understanding needs to exist between organizations and service providers about new role expectations. A lack of coordination in setting standards of role behavior (Mohr and Bitner, 1991) can result in the circulation of conflicting perspectives about the objectives of new roles (Broderick, 1998) and consequently about what is appropriate within new roles (Solomon et al., 1985).

In the following section, we discuss the emergence of new service provider roles in technology-mediated services.

\section{The new service provider roles in technology mediated services}

The increase of technology infusion has changed significantly the context in which services are delivered (Ostrom et al., 2015) and according to recent studies, service providers appear to be taking up new roles. Specifically, prior conceptual studies have identified and classified four new service provider roles; the enabler, differentiator, innovator and coordinator role ( $c f$ Bowen, 2016; Larivière et al., 2017). The adoption of new roles comes from different motivations. For example, one motivation is the need to influence positively technologymediated services (e.g., Galan et al., 2013; Green et al., 2016). This role sees service providers as enablers. It refers to service providers' responsibility to enable both consumers and technology to perform well their respective roles (Bowen, 2016). For example, if consumers have low technology readiness (Mishra et al., 2018; Parasuraman, 2000), the role of service providers is to help them understand how to use the technology at hand. Wünderlich et al. (2013) find that this can be achieved when service providers highlight certain interpersonal aspects of service interactions, e.g., by helping consumers to assert 
control over the service process, by increasing social presence, and by enhancing human trust mechanisms. Connected to the role of enabler, is the differentiator role. By acting as differentiators, service providers are responsible for striking a balance between the 'tech' and ‘touch' elements of service interactions (Giebelhausen et al., 2014; Salomann et al., 2007). This role highlights the 'human touch' element that service providers can bring in technology-mediated services (Larivière et al., 2017). By extension, when this role is performed well, service providers can be seen as 'brand champions' (Lohndorf and Diamantios, 2014). Acting as a brand champion implies the voluntary adoption of citizenship behaviors, which can include adding an authentic 'human touch' element in service interactions (Bowen, 2016).

Another role identified in the literature is the role of innovators. Prior studies suggest that the role of service providers as innovators is vital in the implementation of service innovations (Gottfridsson, 2014). When service providers are involved, the innovation volume (i.e., the number of innovations produced in the course of a year) and innovation radicalness (i.e., the degree of difference between an innovation and existing service offerings) are expected to be stronger (Ordanini and Parasuraman, 2011). Service providers' motivation to innovate depends on global, contextual and situational factors ( $c f$ Cadwallader et al., 2010). For example, if service providers are motivated to be successful in their work, they will be more likely to engage in and perform well in work-related tasks (Cadwallader et al., 2010). Further, service providers can acts as coordinators of multiple actors; these can include several service providers, technology and other resources (Ostrom et al., 2015). Performing this role implies realizing the interdependency between the service provider role, the consumers involved and the technology that is used in a service interaction (Larivière et al., 2017). In essence, in organizations where service providers act as coordinators or 'service orchestrators' it is more likely to reach successful service outcomes, e.g., achieve higher 
levels of consumer satisfaction, and an increase in operational and financial performance (Breidbach, Antons and Salge, 2016).

To sum up, prior service research has identified on a conceptual level new service provider roles that emerge in light of the increase in technology use in services ( $c f$ Bowen, 2016; Larivière et al., 2017). The value of informal influences on technology innovation in healthcare is documented (e.g., DiMartino et al., 2018), however, prior research also suggests that work context shapes organizational role enactment (e.g., Dierdorff, Rubin and Morgeson, 2009). The implication is that new roles are enacted at and affect different levels within the organization. Yet, we still lack empirical support of how taking up new service provider roles can have an impact across different levels (e.g., service delivery level, peer-to-peer level, organizational level). Further, although these roles reflect how service providers might approach technology mediation within their organization, more research is required in order to understand the range of activities that constitute each role and potentially identify other service provider roles.

\section{Methodology}

To derive our theoretical interpretations, we focused on healthcare service providers' discretionary use of technology, such as the use of mobile applications (apps) in the context of healthcare services. Specifically, we focused on mobile apps that support clinical decision making (i.e., diagnosis, investigation, treatment, monitoring and management of diseases) (Free et al., 2010). Our informants used a range of mobile apps designed for healthcare professional use; such as the BNF app that offers information about medicines, the Mersey Micro app that helps in antibiotic prescription and the Mersey Burns app that provides assessments for fluids prescription for burns injuries, amongst others. Although some mobile apps were used by the majority of our informants (e.g., the BNF app), others were specialty- 
specific (e.g., the Mersey Burns app). We chose to focus on discretionary technology use because in contrast to the use of technology introduced at an organizational/firm level, the use of mobile apps, although encouraged to an extent by organizations, rests on the discretion of individual healthcare service providers. Hence, it does not follow a specific pattern or script. Also, there are no clear role expectations (Solomon et al., 1985; Surprenant and Solomon, 1975) associated with discretionary technology use either from the patient perspective or the organizational perspective. For these reasons, we find that service providers have a unique role in the way that technology use is introduced in service delivery, and thus service providers can be instrumental in supporting and encouraging it. As such, we find that this context is ideal for understanding the emergence of new service provider roles. This study follows a qualitative methodology. Data collection comprised in-depth interviews (Belk, Fischer and Kozinets, 2013) with thirty-two healthcare service providers (across twelve specialties, twenty-six male, six female), and an additional five with information governance and management staff (four male, one female). All informants had used mobile apps in their work within the last few months of when the interview took place. The interviews were conducted in person $(n=35)$ and over the phone $(n=2)$. We assigned pseudonyms to participants and simplified professional grades to junior service providers (JSP, i.e., all grades leading to the 'Consultant' level, $\mathrm{n}=16$ ) and senior service providers (SSP, i.e., 'Consultant' level, $\mathrm{n}=16$ ). The role of 'Consultants' in the United Kingdom parallels that of 'Attending physicians' in the United States. In essence, 'Consultants' lead and supervise teams of doctors.

To carry out our study we partnered with an NHS Trust in the north west of England comprising of two large hospitals (all our informants worked in both hospitals) and worked closely with their Research, Development and Innovation (RDI) office for recruitment 
purposes. We contacted potential informants via a global email invitation sent by the RDI office and face-to-face during clinical hours.

All in-depth interviews lasted up to 90 minutes, with the average interview lasting approximately 50 minutes. The interviews were conducted by the first author, were audio recorded and transcribed. During the interview grand tour questions and probes were used (McCracken, 1988). The objective of the interviews was to encourage our informants to share how their individual use of mobile apps for work purposes (the duration of using mobile apps varied from using mobile apps since medical school to discovering them later on in their career) shaped their understanding of emerging service provider roles. More specifically, our informants discussed their experiences with using mobile apps developed both by their organization and by third party companies (e.g., the BNF app). Some of our informants also reflected on their experiences of developing mobile apps within their organization. As the interview progressed, our informants were encouraged to elaborate further about their roles as service providers and their motivation to adopt new roles in their organization.

We identified themes and categories in our data set using a constant comparative logic of coding, categorizing, abstracting, and dimensionalizing (Glaser and Strauss, 1967; Spiggle, 1994), in line with other interpretive qualitative research. This process involved moving back and forth between data collection, data analysis, reflection on the literature and prior theory, and additional data collection (Belk et al., 2013). We concluded data collection when saturation and repetition of themes emerged (Glaser and Strauss, 1967). We also refined our interpretations based on the advice of a research team member experienced in the "lived worlds" of healthcare service providers (Hogg and Maclaran, 2008).

Our coding work involved the use of coding techniques, such as axial and selective coding (Spiggle, 1994). The first step of data analysis involved categorizing and labeling our data according to existing service provider roles identified in the literature (Bowen, 2016; 
Larivière et al., 2017). At this stage we also labeled emerging categories that did not fall in one of the pre-defined roles. Through this process we were able to identify one additional service provider role. The second step involved the identification of attributes and characteristics for each one of the emerging categories, as well as comparisons between them to identify relationships. As our research progressed, we revised our initial set of codes and categories and a theoretical storyline grounded in and driven by our empirical data began to emerge (Hogg and Maclaran, 2008).

\section{Findings}

The analysis of our data confirms that healthcare service providers espouse the roles of enabler, differentiator, innovator and coordinator as previously conceptualized in the literature (e.g., Bowen, 2016; Larivière et al., 2017). We also identify one additional service provider role that is, acting as a sense-giver. The range of activities that constitute each new service provider role are elaborated upon (see Figure 2 for summary) and linkages are drawn between new roles and impact on a service delivery level, a peer-to-peer level, and an organizational level (see Figure 1). As suggested by the arrows in Figure 1, we find that there is indeed a reciprocal influence across levels.

Figure 1 New service provider roles 


\section{The enabler role}

Following the enabler role, healthcare service providers are essentially responsible for ensuring a smooth service delivery in which all parties perform their respective roles well (Bowen, 2016). Tony's narrative highlights the importance of service providers in the process of realizing technology's full potential:

"It's actually how we derive more value from an app, and apps are actually meant to come alive, and at the moment they sort of sit there with the information, and that's not how they should be used for their full potential." (Tony, SSP)

In Tony's terms, to derive value from the use of technology it needs "to come alive". Tony finds that the service provider perspective is vital in this process due to their ability to evaluate the, at the moment, relatively static information produced by mobile app technology. In doing so, service providers can enable technology, such as mobile apps, to thrive in its role and thus bring added value in the technology-mediated service interaction. John explains further how service providers as technology enablers can help consumers experience in a positive way technology-mediated service interactions:

"[I]n an orthopedic job, we had a lot of patients who had fractures of a hip, which unfortunately quite a lot of patients die of. There was an app, and it essentially is something that allows you to estimate the chances of a patient dying within 30 days of 
the hip fracture. It's quite useful to bring the app up, and do it in front of the family and the patient, and say 'look, we can't talk in specifics about any other patients, we can talk specifics about you, we put the details about you', you can say 'it's not an easy operation' and they can see how it works in front of them. Just gives them an idea of what they're going into, and it gives them an outlook of what they're getting into, they may find that quite useful because it involves them in the calculation." (John, JSP)

The extract from the interview with John reflects the importance of his role as enabler in safeguarding that the orthopedic mobile app is used in an appropriate manner in order to inform the patient and their family about a hip fracture operation. John here ensures that there will not be any discrepancy between the patient's expectations about the use of the app as part of their consultation by explaining how the calculations will be worked out specifically for them.

\section{The differentiator role}

Our analysis also reveals that healthcare service providers adopt the differentiator role. As differentiators, service providers are responsible for maintaining a strong 'human touch' element in technology-mediated services (Giebelhausen et al., 2014). Ian discusses his experience:

"It is a helpful tool, as long as it doesn't affect the communication between the doctor and the patient, and takes the eye off the patient. It should only be as an added tool to your patient interaction, and it should also help you and for the patient to understand when you're talking to them, it does help both the doctor and the patient. It should only be a tool to help you enhance the communication with your patient. You have to communicate with the patient. In the importance of the doctor-patient relationship the primary thing is communication. Rather than technology coming between the 
communications and causing a barrier, it should be an added tool to enhance the communication between the patient and yourself, and also being helpful to your work process." (Ian, JSP)

Ian explains the imperative of striking a balance between 'tech' and 'touch' elements in a technology-mediated service (Salomann et al., 2007). In his quote it is evident how easy it is for service providers to become totally immersed in the use of a mobile app and disregard the patient. Whereas by acting as differentiator, Ian illustrates his role in ensuring that the use of technology will not become a communication barrier. Greg elaborates:

"[O]bviously [I] need to be protective, so when I see the patients, I normally tell them before we start off, almost like a verbal consent that 'there are some graphic pictures in this, are you ok with that? It gives you a bit more information so you have a better understanding of what's going on.' Obviously, I think one thing to worry about is if you have stuff on apps that make the patient confused ... If you screen them first, and you see the apps and ... what's relevant to patients, relevant to your discussion and [they] consent, I think it's a good aid." (Greg, SMS)

In Greg's description of using a mobile app with his patients we observe the imperative of the 'human element' in their interaction (Makarem et al., 2009). Greg, being the service provider, regulates the service interaction by revealing certain aspects of the mobile app to the patient. Greg's approach involves screening the technology at hand first in order to double-check if its content is relevant. He then screens the patient in order to understand if they are comfortable with changing an aspect of the traditional doctor-patient interaction, which is to introduce the use of a mobile app. As shown in the literature, patients' technology readiness can vary (Parasuraman, 2000), thus according to Greg, it is vital to show sensitivity on how the patient will experience the technology-mediated service (Bowen, 2016). 


\section{The innovator role}

Our findings suggest that certain healthcare service providers also espouse the innovator role (Bowen, 2016). We find that for our informants adopting this role implies having a clinical input, as insiders, (when possible) in the development of service innovations (e.g., mobile apps) that they use in their work (Nancarrow and Borthwick, 2005). In essence, acting as innovators reinforces the idea of the doctor as leader in patient care. Tom explains: "I find it interesting. Clinical work is obviously my biggest interest, but there's so many other substance to our work, which people think they can't have an influence on, but I think they can if you scratch below the surface, I think you can be having an input and a clinical opinion on it. There's all of them [doctors] complaining about the [IT] systems, and we can just try and help them [technicians] a bit, so that's what I'm interested in." (Tom, SSP)

When asked about his role, Tom expressed that in his point of view, a healthcare service provider can and should have an opinion and an input in the development of service innovations used in the hospital context. In essence, Tom choses to take advantage of his role as an insider (Korica and Molloy, 2010) to become involved in the innovation process instead of being a passive recipient (someone who only resorts to complaining) of ready-made solutions. Another informant, Michael, also advocates about healthcare service providers' active involvement in innovation:

"We sat and thought carefully about where technology could really support patient care, to identify problems we find difficult, and if I say 'we', I mean 'we as doctors', not just us in this hospital, and where the difficulties were something that technology could help solve. Now, the app fitted perfectly because major burns are not frequently seen, but if they're badly managed, it's disastrous for patients. Getting the 
management right makes the difference. It [mobile app] hits every point of the care pathway to improve the care of a patient." (Michael, SSP)

In Michael's opinion, his involvement as an innovator in the development of a mobile app for the assessment of burn injuries comes from a need he identified in a professional level: "we as doctors". Essentially, by being a healthcare service provider, Michael possesses the clarity of judgment and the knowledge to identify where technology use can have a positive impact on patient service (Gottfridsson, 2014). As such, the tangible outcome of his motivation and overall involvement, which is the development of a mobile app, illustrates the importance of service providers' participation in service innovations (Larivière et al., 2017): "it hits every point ... to improve the care of a patient".

\section{The coordinator role}

Based on our informants' narratives, the coordinator role includes the responsibility of healthcare service providers to integrate various resources and manage the multiple actors that are involved in service delivery (Bowen, 2016). Michael talks of his experience of treating patients with major burn injuries:

"The app ... can work out a resuscitation protocol that is accurate, and more than that [it drives] the communication, into an email that can be sent in confidence to [the] Burns unit who know exactly what they are receiving in order to prepare whatever care is demanded when the patient arrives, or to be able to send back advice." (Michael, SSP)

Michael's narrative highlights the interconnectedness between different service encounters across different departments that ultimately inform patients' healthcare journey. In this example, Michael is using the 'email' function of the mobile app in order to coordinate and harmonize all the parties involved (Larivière et al., 2017). Essentially, by 
opening up a direct line of communication with the Burns department, he is able to ensure the consistency of service delivery, 'whatever care is demanded'.

Similarly, when our informants use mobile apps as part of patient service, they report that acting as coordinators enables them to give shape to the overall patient healthcare journey (Lohndorf and Diamantios, 2014). Greg discusses how he coordinates service delivery with other service providers and patients in an example of a physiotherapy mobile app used by himself (i.e., an orthopedic surgeon), a physiotherapist, and the patient:

"Normally when I see patients in clinic, let's say they have a knee injury, I can explain to them what that is, and the app has a little bit more information. [It's] a good one because you see patients and they have the operation done, and after the operation they have to have physiotherapy, and each hospital is slightly different in what regime they use, but it gives the patient the idea ... so they can gaze their progress looking at the app and trying to find out how much benefit they're getting from it. Most of them even discuss the similar guidelines and milestones with the physiotherapists to make sure that they're achieving their targets." (Greg, SSP) Greg introduces the physiotherapy mobile app to patients in order to ensure the consistency of the information they receive (from himself and from physiotherapists) in regard to their surgery and recovery. He mentions that hospitals follow different guidelines for treatment, thus, using a mobile app can provide patients with clarity about their healthcare journey. In addition, patients can evaluate more easily whether their recovery targets are met by involving physiotherapists in the discussion. Although not all patients choose to use the mobile app, for those who do, Greg is able to coordinate their post-surgery plan with physiotherapists. This is achieved indirectly by illustrating to patients, within the mobile app, the milestones and targets that they need to achieve. These milestones and targets are then communicated to physiotherapists by the patient. When acting as coordinators, service 
providers can orchestrate different stages of patients' healthcare journey (Breidbach et al., 2016). However, as seen in the example of Greg, acting as a coordinator does not necessarily imply maintaining control throughout patients' healthcare journey.

\section{The sense-giver role}

The analysis of our dataset further shows that healthcare service providers adopt an additional role in their organization. We find that this role emerges from a need to help others, such as colleagues, to make sense of the ambiguity/confusion regarding technology mediation in services (Gioia and Chittipeddi, 1991) by clarifying and illuminating where the use of mobile apps may appropriately fit within medical practice. This need is manifested as the result of not having a pre-defined and expected set of behaviors (Solomon et al., 1985) associated with the use of mobile apps as part of service delivery. This resolution of ambiguity and creation of intersubjective understandings about the use of mobile apps within the organization is both retrospective and prospective in that we observed retrospection about aspects of use can lead to encouragement for others to change behavior and so a wider alteration of healthcare practice. It is from this combination of interpretation, meaning creation, action and potential for change in the organizational environment (Maitlis and Christianson, 2014) that we describe this role as the sense-giver role (Ashforth, Harrison and Corley, 2008; Maitlis and Christianson, 2014). For example, we found that acting as sense-givers enables healthcare service providers to "provide trajectories for action" (Ashforth et al., 2008, p. 344) by advising others in the organization about how to use technology appropriately. For instance, Taylor and Tony, clarify their guidance to junior healthcare service providers about using mobile apps:

"I've certainly told people about this app, that it's useful and it's accurate, and I've confirmed that by staging patients myself, using that long paperwork approach, so I can say it [mobile app] works and I can recommend it" (Taylor, SSP). 
"The other thing that it [mobile app] allows me to do it, that I can show the team what I'm doing, and they can learn ..., so then they can choose to use the same thing because they've seen me using it and know why I'm using it” (Tony, SSP)

Taylor tells that having confirmed the skin cancer staging process via a mobile app himself, he is able to recommend it to other healthcare service providers. By internalizing the role of the sense-giver, he can help to construct others' discretionary use by providing answers and material of how to deal with technology-mediated services and the appropriate set of behaviors, goals and values that need to be internalized by service providers (Ashforth et al., 2008; Pratt, 2000). In these examples, those observing Taylor's and Tony's behaviour can be inspired to experiment with mobile app use because it is supported by someone within their profession (Nancarrow and Borthwick, 2005).

By extension, healthcare service providers who are seen as role models (Ibarra, 1999) can leverage their role in order to display traits and/or characteristics that can be adopted by others in their organization. Sam explains the importance of sense-giving for shaping junior healthcare service providers' technology use:

“It's something that I did mention because, [t] he person who's on call is junior, I'm worried about them, and I did think it is something that may boost her confidence. I think it was probably a very good thing for me to do and something that I should do again. Actually, it is something that we should make sure that the juniors have the tool; they should have it when they're on call. That should be a part of the induction I think. One, for increasing their confidence, but I'm sure it would help them with management because [they] do make mistakes, and it's usually a confidence thing, but it can also be a knowledge thing. I think it's got to be a good thing for the patients." (Sam, JSP) 
In this quotation Sam explains that technology use can be seen as an important tacit practice that is beneficial not only for the junior healthcare service provider, but also for patients. In the case of Sam, due to his seniority in the organization, he represents a role model in the traditional sense (Ibarra, 1999). Thus, he is in a position to engage in sensegiving and thus to provide answers about appropriate use in order to achieve a positive service outcome for the patient. By acting as a sense-giver, Sam can guide the "meaning construction of others toward a preferred redefinition of organizational reality" (Gioia and Chittipeddi, 1991, p. 442); one that includes the use of mobile apps.

Figure 2 summarizes the range of activities for each one of the new service provider roles.

Figure 2 Range of activities for each role

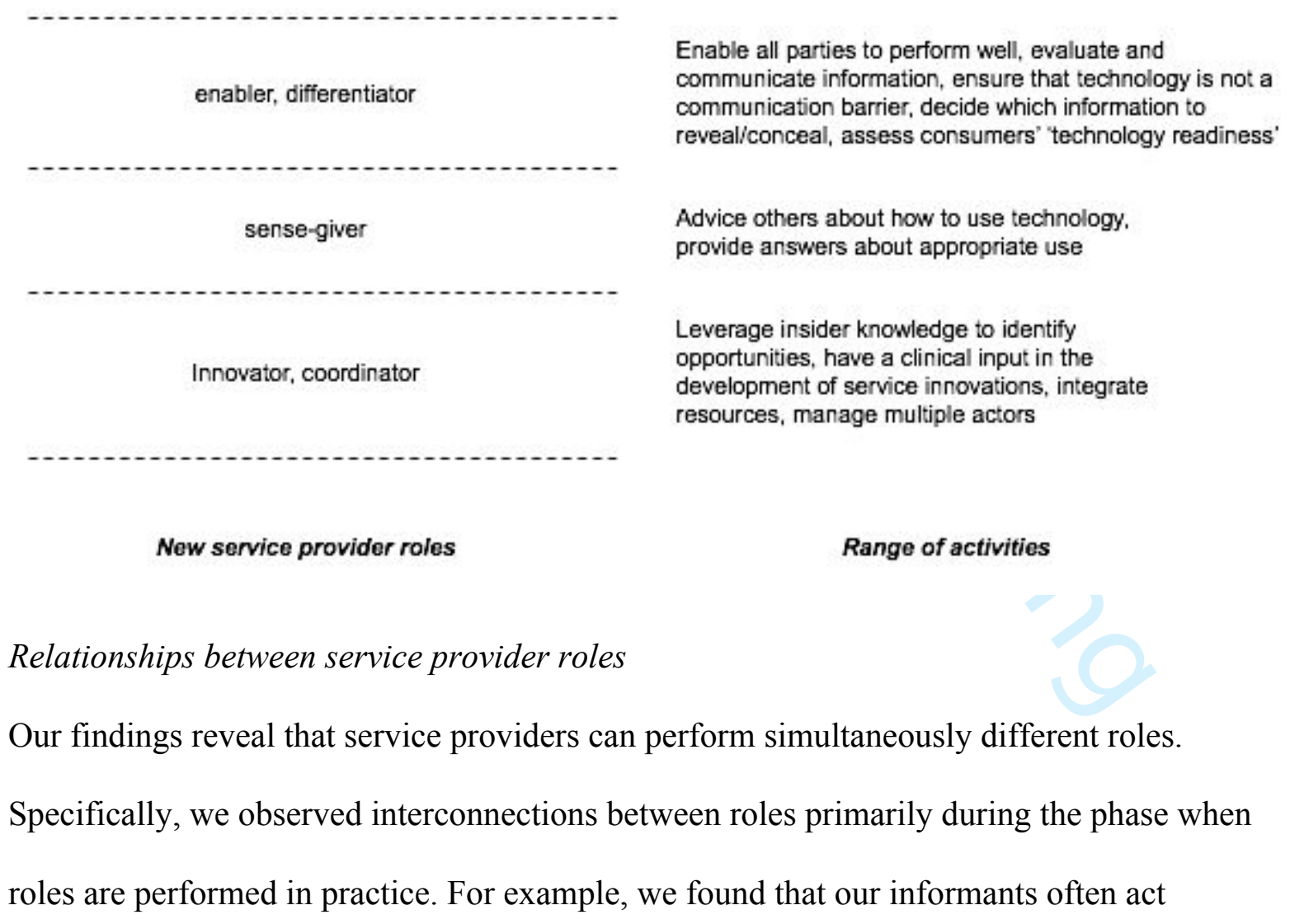

Enable all parties to perform well, evaluate and communicate information, ensure that technology is nota communication barrier, decide which information to Advice others about how to use technology. provide answers about appropriate use Leverage insider knowledge to identify opportunities, have a clinical input in the development of service innovations, integrate 
concurrently as enablers-differentiators in order to meet consumer needs and expectations in regards to the technology-mediated service interaction between them. Paul elaborates:

"It's very embarrassing to ask patients about their weight [..] so I might say [to the patient], "how much do you weigh" and they go "18 stone" and I go "how much should you weigh? Let's have a look what the NHS says." [..] I can tell patients something uncomfortable without it ever been personal. So, I do a little calculation, I do that at the bedside quite a lot now because it is elegant and simple, but it's not me being personal." (Paul, SSP)

Paul explains the importance of being able to show sensitivity when discussing a diagnosis that could be perceived as judgmental otherwise. In essence, his narrative illustrates how, by acting as enabler-differentiator, he is able to safeguard his patients' feelings and thus to control, to some extent, the patient's experience of the technology-mediated service interaction (Bowen, 2016).

Our analysis further illustrates the influence of current roles in the adoption of new roles in the future. Our informants explained that by acting as coordinators, they were able to develop a thorough understanding of patients' healthcare journey (Lohndorf and Diamantios, 2014), which allowed them to identify how technology could be employed to assist themselves and patients in the future. Tom explains:

“We wanted to create a sepsis mobile app. I'm very interested in the management of sepsis, and the recognition and management of sepsis is very poor. It's almost like a patient with sepsis is dying every three to four minutes in the country, and it's the number one cause of death in the UK." (Tom, SSP)

Tom's quotation essentially reveals how his role as coordinator inspired him to take up the innovator role. Tom is a senior healthcare service provider with substantial experience in the treatment of sepsis. As such, having insider knowledge (Korica and Molloy, 2010) of 
the significant problem of mis-recognition and the mis-management of sepsis within healthcare, inclined him to innovate and thus create a mobile app with the purpose of aiding healthcare service providers to treat sepsis effectively.

\section{Discussion}

The aim of this paper was to enhance understanding of the new service provider roles that emerge due to the increase of technology mediation in services. In doing so, we examined the new service provider roles that emerge in a healthcare setting due to the changing nature of the context in which services are delivered (Ostrom et al., 2015). Our findings illustrate that by adopting the role of enabler and differentiator, service providers can have a direct impact on a service delivery level, by adopting the role of coordinator and innovator, service providers can have a direct impact on an organizational level and by adopting the role of sense-giver, service providers can have a direct impact on a peer-to-peer level (see Figure 1). However, by adopting new roles, service providers can also have an indirect impact across levels. For example, by being involved in the development of new technology as innovators, service providers can influence service delivery when their innovations are used in their departments. In essence, our analysis revealed the necessity of taking up new roles in order to be able to positively influence technology-mediated service outcomes (Schumann et al., 2012).

This study contributes to literature on technology-mediated services in three ways. First, by illustrating empirically the range of activities that constitute each role. By documenting how each new role unfolds we were able to identify relationships between them in terms of service providers' motivations and actual service outcomes. This extends prior conceptual work (e.g., Bowen, 2016; Larivière et al., 2017). For our informants the conceptual "boundaries" between roles were less distinctive in comparison to prior 
theorizations, although there are clear similarities in terms of the tasks performed in each role. For example, the enabler and differentiator role were closely connected. Healthcare service providers' narratives revealed that acting as both an enabler and differentiator allowed them to meet consumer needs and expectations in regards to the technologymediated service interaction between them. This involves screening the technology to evaluate if it can fulfill its purpose, and also screening consumers in terms of their technology readiness (Mishra et al., 2018; Parasuraman, 2000) and willingness to change an expected element of the service process. By maintaining a strong 'human touch' element during the technology-mediated service delivery (Makarem et al., 2009) service providers were able to support all parties to perform well in their respective roles. As such, holding a balance between 'tech' and 'touch' elements (Giebelhausen et al., 2014) enabled service providers to meet consumers' demands and to eliminate the uncertainty that is associated with changes in pre-defined modes of service delivery (Schau et al., 2007). The analysis of our dataset further revealed that interconnections between roles emerge not only during the phase when roles are performed in practice (e.g., enabler-differentiator), but also the influence of current roles in the adoption of new roles in the future. For example, our informants reported that acting as coordinators helped them to overlook the overall patient healthcare journey, and thus were able to identify where the use of new technology innovations (e.g., mobile apps) could support patients and healthcare service providers.

This paper also complements previous studies by illustrating that prior classifications of service provider roles are not exhaustive (e.g., e.g., Bowen, 2016; Larivière et al., 2017). In practice, service providers go beyond acting as enablers, differentiators, coordinators and innovators. More specifically, our in-depth analysis of our informants' interviews revealed that service providers adopt the additional role of sense-giver (Ashforth et al., 2008). The emergence of this role follows the need to help others, such as colleagues, in their 
construction of meaning about technology mediation in services (Gioia and Chittipeddi, 1991). By adopting this role healthcare service providers were able to disseminate their insider knowledge (Korica and Molloy, 2010) by advising others in the organization about how to use technology appropriately. By extension, the sense-giver role allowed healthcare service providers to act as role models within their organization (Ibarra, 1999).

Finally, this study revealed that by taking on these roles (or to be more precise, combinations of these roles) service providers were able to encourage, support and advance technology mediation in services across different groups or audiences in their organization (e.g., service delivery level, peer-to-peer level, organizational level). From a combination of the enabler and differentiator role, service providers were able to help consumers to understand the added value of technology-mediation in the traditional provider-consumer service interaction. By acting as sense-givers, service providers were able to help others to interpret how technology use is changing services (Schumann et al., 2012) and how service providers can stay on top of these changes by sharing their individual experiences of (appropriate) technology use. In addition, by becoming role models in the traditional sense (Ibarra, 1999), sense-givers portrayed a range of new behaviors, attitudes and skills that could be adopted by other service providers (Pratt, 2000). Finally, taking up the innovator and coordinator roles enabled service providers to have an impact at an organizational level. By coordinating multiple actors and resources service providers were able to monitor the overall consumer (or 'customer') journey. As a result they could also identify the aspects of the technology-mediated service delivery that could be improved in order to enhance patient satisfaction (Bitner et al., 2000). The innovator role enabled service providers to have a clinical input, as insiders (Korica and Molloy, 2010) in the development of the technology that they use in their work. Importantly, they could provide insight and influence the development of the technology from within their profession (Nancarrow and Borthwick, 
2005) ensuring that the technology that is developed and used comes from a place of insider knowledge (Gottfridsson, 2014) of consumer needs.

\section{Practical implications}

This study holds a number of implications for practice. From a practical perspective, the use of mobile apps introduces a range of opportunities and obstacles for service organizations (Newman et al., 2018). As such, we believe that the first step for service organizations should be to identify the new service provider roles that emerge within their organization, and consequently identify the service providers that are espousing new roles (e.g., those who are involved in innovation) (Gottfridson, 2014). Second, organizations need to produce guidelines that set the new standards of role behavior (Mohr and Bitner, 1991) in light of the increase in technology mediation (Bitner et al., 2000). For example, in our context, the management and information governance team launched a 'mobile device use' policy with the aim of regulating the use of technology by informing their staff of what they could and could not do with mobile devices. Adding some governance in place can offer service providers a detailed overview of the preferred model of behavior they should enact in the organization (Pratt, 2000). We believe that it is important to have a common understanding between organizations and service providers about new role expectations in order to ensure that service providers are aware of what is considered appropriate within new roles (Solomon et al., 1985), and what are the common objectives of new roles (Broderick, 1998).

From a consumer satisfaction perspective (Bitner et al., 2000), it is important to clarify new roles because consumers' expectations of how the provider is going to behave need to be met. For example, our informants praised a marketing campaign aiming to inform patients about the potential use of mobile apps during their consultations with a healthcare service provider by displaying posters throughout the NHS Trust. However, service 
organizations also need to provide additional training for service providers in order to help them manage potential role discrepancies (Broderick, 1998). Not meeting expectations can easily lead to consumer uncertainty and dissatisfaction (Schau et al., 2007). Thus, it is vital to educate service providers about the new roles they can adopt in the context of a technologymediated service interaction in order to help avoid inefficiency and additional costly errors (Schau et al., 2007).

\section{Research limitations and future avenues}

This study is not without limitations. We conducted an in-depth qualitative study, however, our theorizations are drawn from the U.K. healthcare context. Although healthcare shares many similarities with other professional service contexts (Berry and Bendapudi, 2007), future research should investigate other service industries and countries. This study has focused on uncovering service providers' perspective of emerging new roles due to the increase of technology use in services. However, we have not delved into to the potential changes in self-definitions that may be produced by adopting new roles (Ibarra, 1999). A promising area for future research is to examine how new skills, behaviors and interactions associated with espousing a new role affect service providers' professional identity.

Future studies can also extend this line of work by unpacking consumers' evaluations of service providers' new roles. Empirical work in this area can investigate how consumers respond to service providers who adopt new roles. Future studies can also investigate, from a consumer perspective, how the technology-mediated service interaction is affected, either positively or negatively, when service providers espouse roles that are more linked with service delivery (e.g., acting as enablers or differentiators). 


\section{References}

Ashforth, B.E., Harrison, S.H. and Corley, K.G. (2008), "Identification in organizations: An examination of four fundamental questions", Journal of Management, Vol. 34 No. 3, pp. 325374.

Belk, R., Fischer, E. and Kozinets, R.V. (2013), Qualitative consumer and marketing research, Sage, London.

Berry, L.L. and Bendapudi, N. (2007), "Health care a fertile field for service research", Journal of Service Research, Vol. 10 No. 2, pp. 111-122.

Biddle, B.J. (1986), "Recent Developments in Role Theory”, Annual Review of Sociology, Vol. 12, pp. 67-92.

Bitner, M.J., Brown, S.W. and Meuter, M.L. (2000), "Technology infusion in service encounters", Journal of the Academy of Marketing Science, Vol. 28 No.1, pp. 138-149. Bitner, M.J., Booms, B.H. and Mohr, L.A. (1994), "Critical service encounters: The employee's viewpoint”, Journal of Marketing, Vol. 58 No. 4, pp. 95-106.

Blut, M., Wang, C. and Schoefer, K. (2016), "Factors Influencing the Acceptance of SelfService Technologies A Meta-Analysis”, Journal of Service Research, Vol. 19 No. 4, pp. $396-416$.

Bowen, D.E. (2016), “The changing role of employees in service theory and practice: An interdisciplinary view”, Human Resource Management Review, Vol. 26 No. 1, pp. 4-13. Breidbach, C.F., Antons, D. and Salge, T.O. (2016), "Seamless service? On the role and impact of service orchestrators in human-centered service systems", Journal of Service Research, Vol. 19 No. 4, pp. 458-476.

Broderick, A.J. (1998), “Role theory, role management and service performance”, Journal of Services Marketing, Vol. 12 No. 5, pp. 348-361. 
Cadwallader, S., Jarvis, C.B., Bitner, M.J. and Ostrom, A.L. (2010), "Frontline employee motivation to participate in service innovation implementation", Journal of the Academy of Marketing Science, Vol. 38 No. 2, pp. 219-239.

Chowdhury, R.I., Patro, S., Venugopal, P. and Israel, D. (2014), “A study on consumer adoption of technology-facilitated services", Journal of Services Marketing, Vol. 28 No. 6, pp. 471-483.

Dierdorff, E.C., Rubin, R.S. and Morgeson, F.P. (2009), “The milieu of managerial work: An integrative framework linking work context to role requirements", Journal of Applied Psychology, Vol. 94 No. 4, pp. 972-988.

DiMartino, L.D., Birken, S.A., Hanson, L.C., Trogdon, J.G., Clary, A.S., Weinberger, M., Reeder-Hayes, K. and Weiner, B.J. (2018), “The influence of formal and informal policies and practices on health care innovation implementation: A mixed-methods analysis", Health Care Management Review, Vol. 43 No. 3, pp. 249-260.

Fisk, R.P., Dean, A.M., Alkire (née Nasr), L., Joubert, A., Previte, J., Robertson, N. and Rosenbaum, M.S. (2018), "Design for service inclusion: creating inclusive service systems by 2050”, Journal of Service Management, https://doi.org/10.1108/JOSM-05-2018-0121. Free, C., Phillips, G., Felix, L., Galli, L., Patel, V., and Edwards, P. (2010), “The effectiveness of M-health technologies for improving health and health services: a systematic review protocol", BMC research notes, Vol. 3 No. 250, pp. 1-7.

Gallan, A.S., Jarvis, C.B., Brown, S.W. and Bitner, M.J. (2013), “Customer positivity and participation in services: an empirical test in a health care context", Journal of the Academy of Marketing Science, Vol. 41 No. 3, pp. 338-356.

Giebelhausen, M., Robinson, S.G., Siriani, N. and Brady, M. (2014), “Touch vs. Tech: When Technology Functions as a Barrier or a Benefit to Service Encounters", Journal of Marketing, Vol. 78 No. 4, 113-124. 
Gioia, D.A. and Chittipeddi, K. (1991), "Sensemaking and Sensegiving in Strategic Change Initiation”, Strategic Management Journal, Vol. 12 No. 6, pp. 433-48.

Glaser, B.S. and Strauss, A. (1967) The Discovery of Grounded Theory: Strategies for Qualitative Research, Aldine, Chicago.

Glushko, R.J. and Nomorosa, K.J. (2013), “Substituting information for interaction: A framework for personalization in service encounters and service systems", Journal of Service Research, Vol. 16 No. 1, pp. 21-38.

Gottfridsson, P. (2014), “Different actors' roles in small companies service innovation”, Journal of Services Marketing, Vol. 28 No. 7, pp. 547-557.

Green, T., Hartley, N. and Gillespie, N. (2016), “Service Provider's Experiences of Service Separation: The Case of Telehealth", Journal of Service Research, Vol. 19 No. 4, pp. 477494.

Hogg, M.K. and Maclaran, P. (2008), "Rhetorical issues in writing interpretivist consumer research", Qualitative Market Research: An International Journal, Vol. 11 No. 2, pp. 130146.

Hubbert, A.R., Garcia Sehorn, A. and Brown, S.W. (1996), "Service Expectations: The Consumer vs. the Provider", International Journal of Service Industry Management, Vol. 6 No. 1 , pp. 6-21.

Ibarra, H. (1999), "Provisional selves: Experimenting with image and identity in professional adaptation”, Administrative Science Quarterly, Vol. 44 No. 4, pp. 764-791.

Keh, H.T. and Pang, J. (2010), “Customer reactions to service separation”, Journal of Marketing, Vol. 74 No. 2, pp. 55-70.

Korica, M. and Molloy, E. (2010), "Making sense of professional identities: Stories of medical professionals and new technologies", Human Relations, Vol. 63 No. 12, pp. 18791901. 
Larivière, B., Bowen, D., Andreassen, T.W., Kunz, W., Sirianni, N.J., Voss, C., Wünderlich, N.V. and De Keyser, A. (2017), "Service Encounter 2.0": An investigation into the roles of technology, employees and customers", Journal of Business Research, Vol. 79, pp. 238-246. Löhndorf, B. and Diamantopoulos, A. (2014), "Internal branding: Social identity and social exchange perspectives on turning employees into brand champions", Journal of Service Research, Vol. 17 No. 3, pp. 310-325.

Maitlis, S. and Christianson, M. (2014), "Sensemaking in organizations: Taking stock and moving forward", The Academy of Management Annals, Vol. 8 No. 1, pp. 57-125.

Makarem, S.C., Mudambi, S.M. and Podoshen, J.S. (2009), "Satisfaction in technologyenabled service encounters", Journal of Services Marketing, Vol. 23 No. 3, pp. 134-144. McCracken, G. (1988), The long interview, Sage, Newbury Park. Mishra, A., Maheswarappa, S.S. and Colby, C.L. (2018), “Technology readiness of teenagers: a consumer socialization perspective", Journal of Services Marketing, Vol. 32 No. 5, pp. 592-604.

Mohr, L.A. and Bitner, M.J. (1991), "Mutual Understanding Between Customers and Employees in Service Encounters", Holman, R.H. and Solomon, M.R., Advances in Consumer Research, Association for Consumer Research, Provo, UT, pp. 611-17. Nancarrow, S.A. and Borthwick, A.M. (2005), "Dynamic professional boundaries in the healthcare workforce", Sociology of Health and Illness, Vol. 27 No. 7, pp. 897-919. Newman, C.L., Wachter, K. and White, A. (2018), "Bricks or clicks? Understanding consumer usage of retail mobile apps", Journal of Services Marketing, Vol. 32 No. 2, pp. 211-222.

Ordanini, A. and Parasuraman, A. (2011), "Service innovation viewed through a servicedominant logic lens: A conceptual framework and analysis", Journal of Service Research, Vol. 14 No. 1, pp. 3-33. 
Ostrom, A.L., Parasuraman, A., Bowen, D.E., Patricio, L. and Voss, C.A. (2015), “Service Research Priorities in a Rapidly Changing Context", Journal of Service Research, Vol. 18 No.2, pp. 127-59.

Parasuraman, A. (2000), “Technology Readiness Index (TRI) a multiple-item scale to measure readiness to embrace new technologies", Journal of Service Research, Vol. 2 No. 4, pp. 307-320.

Pratt, M.G. (2000), “The good, the bad, and the ambivalent: Managing identification among Amway distributors", Administrative Science Quarterly, Vol. 45 No. 3, pp. 456-493.

Salomann, H., Malte D., Lutz K., and Brenner, W. (2007), “Self-Service Revisited: How to Balance High-Tech and High-Touch in Customer Relationships", European Management Journal, Vol. 25 No. 4, pp. 310-19.

Schau, H.J., Dellande, S. and Gilly, M.C. (2007), “The impact of code switching on service encounters", Journal of Retailing, Vol. 83 No. 1, pp. 65-78.

Schumann, J.H., Wünderlich, N.V. and Wangenheim, F. (2012), “Technology Mediation in Service Delivery: A New Typology and an Agenda for Managers and Academics", Technovation, Vol. 32 No. 2, pp. 133-43.

Solomon, M.R., Surprenant, C., Czepiel, J.A., and Gutman, E.G. (1985), “A role theory perspective on dyadic interactions: the service encounter", Journal of Marketing, Vol. 49 No. 1, pp. 99-111.

Spiggle, S. (1994), “Analysis and Interpretation of Qualitative Data in Consumer Research”, Journal of Consumer Research, Vol. 21 No. 3, pp. 491-503.

Surprenant, C.F. and Solomon, M.R. (1987), "Predictability and personalization in the service encounter", Journal of Marketing, Vol. 51 No. 2, pp. 86-96. 
Wünderlich, N.V., Wangenheim, F.V. and Bitner, M.J. (2013), "High tech and high touch: a framework for understanding user attitudes and behaviors related to smart interactive services", Journal of Service Research, Vol. 16 No. 1, pp. 3-20. 


\section{Supplementary Review File}

We would like to thank the Associate Editor and the two Reviewers for their extremely helpful and insightful feedback and comments, which have helped us to move our paper forward and strengthen its contribution. Following your suggestions, we have structured our revisions using four main revision themes, namely theory and literature review, findings, methodology and stylistic issues. We will now discuss below how we have addressed the Reviewers' comments on a point by point basis. In closing, we reiterate our thanks to the Associate Editor and Reviewers, and look forward to the outcome of the next stage in the review process.

\begin{tabular}{|c|c|c|c|}
\hline \multicolumn{3}{|c|}{ Reviewers' comments } & \multirow{3}{*}{ Actions/Responses } \\
\hline & Reviewer 2 & Reviewer 4 & \\
\hline \multicolumn{2}{|c|}{$\begin{array}{l}\text { Revision themes } \\
\text { 1. Theory and literature review }\end{array}$} & & \\
\hline 1.1. & $\begin{array}{l}\text { When we get to Figure 1, the authors } \\
\text { have discussed the "New service } \\
\text { provider roles" in the "Literature } \\
\text { review" chapter. However, I believe it } \\
\text { would also be relevant to introduce } \\
\text { shortly the three levels of impact in the } \\
\text { "Literature review" chapter as well - } \\
\text { just so the reader is familiar with these } \\
\text { three levels when exposed to it in } \\
\text { Figure } 1 . \text { This can be done shortly and in } \\
\text { a general manner. }\end{array}$ & 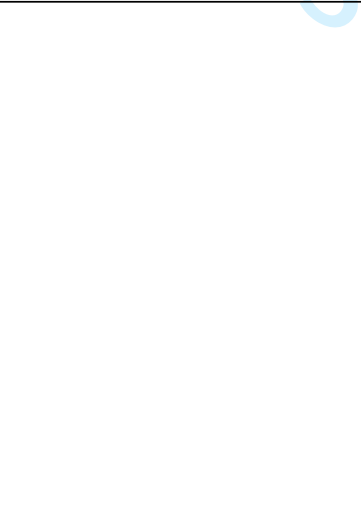 & $\begin{array}{l}\text { We thank Reviewer } 2 \text { for the suggestion to make a short } \\
\text { mention of the three levels of impact in the "Literature review" } \\
\text { section to familiarise the reader with the idea. We included a } \\
\text { short description in the last paragraph of the literature review } \\
\text { (p. 7). }\end{array}$ \\
\hline
\end{tabular}




\begin{tabular}{|c|c|c|}
\hline 1.2 & $\begin{array}{l}\text { It is not intuitive why e.g. enabler is } \\
\text { related to "Service delivery level" (and } \\
\text { not the two other levels). I believe a } \\
\text { discussion as suggested in my bullet } \\
\text { point above may also contribute to } \\
\text { clarify this. }\end{array}$ & $\begin{array}{l}\text { We thank Reviewer } 2 \text { for urging us to reconsider the impact of } \\
\text { roles on different levels. Indeed, we agree with Reviewer } 2 \text { that } \\
\text { some roles can have an impact across levels. Consequently, we } \\
\text { highlight (page 20-21) that the principal influence of enabler } \\
\text { and differentiator roles is directly at the service delivery level } \\
\text { and the principal influence of the innovator and coordinator } \\
\text { roles is directly at the organizational level while also } \\
\text { acknowledging that roles can have an indirect influence across } \\
\text { levels. }\end{array}$ \\
\hline 1.3. & $\begin{array}{l}\text { I believe the arrows in Figure } 1 \text { are } \\
\text { interesting (and I understand this as the } \\
\text { relationships between the roles - } \\
\text { pointed out in purpose } 1 \text { ). As far as I can } \\
\text { see, they are not commented on before } \\
\text { we get to the Discussion chapter. You } \\
\text { do mention "relationships between the } \\
\text { roles" as part of purpose } 1 . \text { I think it } \\
\text { would be relevant to shortly reflect on } \\
\text { the arrows either } 1 \text { ) in the part I suggest } \\
\text { you include in my bullet point above or } \\
\text { 2) shortly after the introduction of } \\
\text { Figure } 1 .\end{array}$ & $\begin{array}{l}\text { We thank Reviewer } 2 \text { for the recommendation to provide a } \\
\text { short reflection about the role of the arrows in Figure } 1 \text {. We } \\
\text { have now included an explanation before the introduction of } \\
\text { Figure } 1 \text { in the first paragraph of the Findings section (given } \\
\text { here for reviewer convenience): "The range of activities that } \\
\text { constitute each new service provider role are elaborated upon } \\
\text { (see Figure } 2 \text { for summary) and linkages are drawn between } \\
\text { new roles and impact on a service delivery level, a peer-to-peer } \\
\text { level, and an organizational level (see Figure 1). As suggested by } \\
\text { the arrows in Figure } 1 \text { we find that there is indeed a reciprocal } \\
\text { influence across levels." }\end{array}$ \\
\hline 1.4. & $\begin{array}{l}\text { Given that "relationships between the } \\
\text { roles" is an issue here; Would it be } \\
\text { interesting to include this as a sixth part } \\
\text { of the Findings chapter? That you keep } \\
\text { the discussion of the five roles as is - } \\
\text { and then include a sixth part called } \\
\text { something like "Relationships between } \\
\text { the roles". The way I read your }\end{array}$ & $\begin{array}{l}\text { We thank Reviewer } 2 \text { for the sensible recommendation to } \\
\text { include a sixth part in our Findings section in order to make our } \\
\text { contribution on the relationship between roles more explicit. As } \\
\text { such, we included a sixth theme called "Relationships between } \\
\text { service provider roles" (p. 19-21). }\end{array}$ \\
\hline
\end{tabular}




\begin{tabular}{|c|c|c|c|}
\hline & $\begin{array}{l}\text { Discussion chapter, you seem to have } \\
\text { some empirical insight on the } \\
\text { interconnections between the roles } \\
\text { (e.g. your last sentence on page } 20 \\
\text { gives such an indication). This would } \\
\text { also make your contribution on the } \\
\text { "Relationship between the roles" } \\
\text { (pointed out in Purpose } 1 \text { ) more } \\
\text { explicit. }\end{array}$ & 0 & \\
\hline 1.5. & $\begin{array}{l}\text { The purpose of the manuscript is clear, } \\
\text { and the theoretical and empirical part } \\
\text { deliver on the purpose. }\end{array}$ & $\begin{array}{l}\text { Problem statement is unclear. Why was this } \\
\text { setting/research subject chosen? Is there } \\
\text { some issue or role confusion among the } \\
\text { service providers? Are they being deficient in } \\
\text { service or use of the mobile app? } \\
\text { Firstly, the problem statement and issue at } \\
\text { hand has not been fully articulated. Why was } \\
\text { this setting chosen? Are there documented } \\
\text { challenges regarding hospital service } \\
\text { providers (JSP, SSP) understanding their } \\
\text { roles or implementing/using these mobile } \\
\text { apps? } \\
\text { No clear justification is provided as to why } \\
\text { this setting was selected for research. } \\
\text { Hence, practical implications are not readily } \\
\text { inferenceable. }\end{array}$ & $\begin{array}{l}\text { We thank Reviewer } 4 \text { for urging us to further clarify our } \\
\text { problem statement. As described in our methodology section: } \\
\text { "We chose to focus on discretionary technology use because in } \\
\text { contrast to the use of technology introduced at an } \\
\text { organizational/firm level, the use of mobile apps, although } \\
\text { encouraged to an extent by organizations, rests on the } \\
\text { discretion of individual healthcare service providers. Hence, it } \\
\text { does not follow a specific pattern or script. Also, there are no } \\
\text { clear role expectations (Solomon et al., 1985; Surprenant and } \\
\text { Solomon, 1975) associated with discretionary technology use } \\
\text { either from the patient perspective or the organizational } \\
\text { perspective. For these reasons, we find that service providers } \\
\text { have a unique role in the way that technology use is introduced } \\
\text { in service delivery, and thus service providers can be } \\
\text { instrumental in supporting and encouraging it. As such, we find } \\
\text { that this context is ideal for understanding the emergence of } \\
\text { new service provider roles." } \\
\text { In terms of documented challenges regarding hospital service } \\
\text { providers (JSP, SSP) understanding their roles or } \\
\text { implementing/using these mobile apps: Our study finds that not } \\
\text { having a pre-defined and expected set of behaviors (Solomon et }\end{array}$ \\
\hline
\end{tabular}




\begin{tabular}{|c|c|c|c|}
\hline & & & $\begin{array}{l}\text { al., 1985) associated with the use of mobile apps as part of } \\
\text { service delivery created the need for certain service providers } \\
\text { to take-up the role of sense-givers. This role emerged from a } \\
\text { need to help others, such as colleagues, to make sense of the } \\
\text { ambiguity/confusion regarding technology mediation in } \\
\text { services (Gioia and Chittipeddi, 1991) by clarifying and } \\
\text { illuminating where the use of mobile apps may appropriately fit } \\
\text { within medical practice. } \\
\text { We also included more up-to-date references to support the } \\
\text { purpose of our study and join in the current conversations in } \\
\text { service literature. }\end{array}$ \\
\hline 1.6. & & $\begin{array}{l}\text { While reference has been made to role } \\
\text { theory and role definitions from existing } \\
\text { studies, the definitions have been loosely } \\
\text { correlated to the author's own role } \\
\text { definitions (enabler, differentiator, } \\
\text { coordinator, innovator). There needs to be } \\
\text { more rigor to sticking to published } \\
\text { definitions when extending the same to } \\
\text { other studies. For example the reference } \\
\text { papers state "Each role has to be learned", } \\
\text { "Clearly defined roles are a pre-requisite for } \\
\text { applying role theory", which may not be the } \\
\text { case in this paper. The authors have taken a } \\
\text { more fluid approach to defining roles in their } \\
\text { study. }\end{array}$ & $\begin{array}{l}\text { Thank you for your observation. In the Literature review sub- } \\
\text { section, 'The new service provider roles in technology mediated } \\
\text { services', we provide a clear definition of each service provider } \\
\text { role as they are defined in prior research (cf Bowen, 2016; } \\
\text { Larivière et al., 2017). We hope this clarifies the definition of } \\
\text { the roles identified up to now in the literature for the reader } \\
\text { and that in this study we have not deviated from prior } \\
\text { definitions for those roles. }\end{array}$ \\
\hline \multicolumn{2}{|c|}{ 2. Findings } & & Z \\
\hline 2.1 & $\begin{array}{l}\text { (Re Abstract) Take a look at the last } \\
\text { sentence in Findings. Is it important } \\
\text { enough to include here? Maybe rather }\end{array}$ & & $\begin{array}{l}\text { In response to this sensible suggestion, we have now changed } \\
\text { the last sentence in the abstract accordingly: "This paper }\end{array}$ \\
\hline
\end{tabular}




\begin{tabular}{|c|c|c|c|}
\hline & $\begin{array}{l}\text { include a sentence about the } \\
\text { relationships between the roles. }\end{array}$ & & $\begin{array}{l}\text { further shows the relationships between these new service } \\
\text { provider roles." }\end{array}$ \\
\hline 2.2 & & $\begin{array}{l}\text { A new role definition (sense-giver) has to be } \\
\text { clearly defined and if possible backed by } \\
\text { quantitative studies. This is missing. }\end{array}$ & $\begin{array}{l}\text { We thank Reviewer } 4 \text { for urging us to define more clearly the } \\
\text { sense-giver role. On page 17-18 we amend the text to give } \\
\text { greater clarity and justification of the label 'sense-giver' (given } \\
\text { here for your convenience): } \\
\text { "We find that this role emerges from a need to help others, such } \\
\text { as colleagues, to make sense of ambiguity regarding technology } \\
\text { mediation in services (Gioia and Chittipeddi, 1991) by clarifying } \\
\text { and illuminating where the use of medical apps may } \\
\text { appropriately fit within medical practice. This need is } \\
\text { manifested as the result of not having a pre-defined and } \\
\text { expected set of behaviors (Solomon et al., 1985) associated with } \\
\text { the use of mobile apps as part of service delivery. This resolution } \\
\text { of ambiguity and creation of intersubjective understandings } \\
\text { about the use of mobile apps within the organization is both } \\
\text { retrospective and prospective in that we observed retrospection } \\
\text { about aspects of use can lead to encouragement for others to } \\
\text { change behavior and so a wider alteration of healthcare } \\
\text { practice. It is from this combination of interpretation, meaning } \\
\text { creation, action and potential for change in the organizational } \\
\text { environment (Maitlis and Christianson, 2014) that we describe } \\
\text { this role is described as the sense-giver role (Ashforth, Harrison } \\
\text { and Corley, 2008; Maitlis and Christianson 2014)." } \\
\text { In the context of an interpretive methodology with } 37 \\
\text { informants and rigorous attention to the qualitative analysis } \\
\text { that also supported previous research findings concerning } \\
\text { service provider roles, we feel that our findings provide } \\
\text { sufficient in-depth understanding of the new service provider } \\
\text { role and support for the new definition to stand without }\end{array}$ \\
\hline
\end{tabular}




\begin{tabular}{|c|c|c|c|}
\hline & & & $\begin{array}{l}\text { quantitative support at this point. Please see point 3.3. for } \\
\text { further clarification. }\end{array}$ \\
\hline 2.3 . & & $\begin{array}{l}\text { Some of the implications do not seem to } \\
\text { basis in the findings. For example, in the } \\
\text { implications section, there is a reference to } \\
\text { security in the mobile app and usage policy } \\
\text { on the mobile device, which do not have any } \\
\text { reference in the earlier sections. }\end{array}$ & $\begin{array}{l}\text { Thank you for your observation. We agree that our reference to } \\
\text { security in the mobile app and usage policy on the mobile } \\
\text { device, was not referenced in the earlier sections. The existing } \\
\text { length of the paper and other revisions preclude much addition } \\
\text { to remedy this point, so we removed this comment. }\end{array}$ \\
\hline \multicolumn{4}{|c|}{ 3. Methodology } \\
\hline 3.1 . & $\begin{array}{l}\text { Methodology and research context, first } \\
\text { paragraph: I recommend that the } \\
\text { authors include one sentence here } \\
\text { providing two or three concrete } \\
\text { examples of apps. I believe that will give } \\
\text { the reader a better contextual } \\
\text { understanding (we get an } \\
\text { understanding of the apps in the } \\
\text { Findings chapter - but I believe it will } \\
\text { help the reader to get some examples } \\
\text { already here). }\end{array}$ & $\begin{array}{l}\text { No effort has been made to justify the } \\
\text { 'uniqueness' of mobile-based technology } \\
\text { mediation in a hospital based service setting. } \\
\text { It appears more of a convenience based } \\
\text { choosing of this setting. Mobile apps and } \\
\text { tele-health have different applications - } \\
\text { ranging from self-service (self-diagnosis) to } \\
\text { intervention-based apps and also to Al- } \\
\text { based apps (knowledge based apps to } \\
\text { support clinical decision making). By not } \\
\text { identifying and standardizing the apps under } \\
\text { research, the applicability of the responses is } \\
\text { open to questioning. }\end{array}$ & $\begin{array}{l}\text { We thank both Reviewers for urging us to clarify more clearly } \\
\text { the types of mobile apps that were used by our informants. In } \\
\text { response, and following the recommended positioning of } \\
\text { Reviewer 2, in the first paragraph of the methodology and } \\
\text { research context section we provide three concrete examples } \\
\text { of apps. We agree that identifying the apps as designed for } \\
\text { healthcare professional use and supporting clinical decision } \\
\text { making will give the reader a better contextual understanding } \\
\text { and endorse the applicability of the responses. } \\
\text { We included the following information: "Specifically, we } \\
\text { focused on mobile apps that support clinical decision making } \\
\text { (i.e., diagnosis, investigation, treatment, monitoring and } \\
\text { management of diseases) (Free et al., 2010). Our informants } \\
\text { used a range of mobile apps designed for healthcare } \\
\text { professional use; such as the BNF app that offers information } \\
\text { about medicines, the Mersey Micro app that helps in antibiotic } \\
\text { prescription and the Mersey Burns app that provides } \\
\text { assessments for fluids prescription for burns injuries, amongst } \\
\text { others. Although some mobile apps were used by the majority of } \\
\text { our informants (e.g., the BNF app), others were specialty- } \\
\text { specific (e.g., the Mersey Burns app)." (p. 7) }\end{array}$ \\
\hline
\end{tabular}




\begin{tabular}{|c|c|c|c|}
\hline 3.2 & $\begin{array}{l}\text { The authors write "...., our informants } \\
\text { were encouraged to elaborate about } \\
\text { changes they experienced in their roles } \\
\text { as service providers...(my italic)". How } \\
\text { relevant information is this, given that } \\
\text { you do not study changes in roles? }\end{array}$ & & $\begin{array}{l}\text { Thank you for your observation. We agree with your argument } \\
\text { that it is not particularly relevant to include this information } \\
\text { here since we do not study changes in roles. We amended the } \\
\text { sentence accordingly: "As the interview progressed, our } \\
\text { informants were encouraged to elaborate further about their } \\
\text { roles as service providers and their motivation to adopt new } \\
\text { roles in their organization." }\end{array}$ \\
\hline 3.3. & & $\begin{array}{l}\text { The paper misses on proper rigor around the } \\
\text { research methodology and documentation. } \\
\text { This is a qualitative research based study and } \\
\text { hence is open to multiple opinions. } \\
\text { Being a qualitative research the outcome is } \\
\text { primarily exploratory. The analysis and } \\
\text { results are subject to personal } \\
\text { interpretation. While results and author's } \\
\text { interpretation are leading to } \\
\text { new/incremental findings, I would be wary } \\
\text { of leading with these findings, without } \\
\text { validated by quantitative studies. }\end{array}$ & $\begin{array}{l}\text { Whilst appreciating the positivist viewpoint, in response to the } \\
\text { comments of Reviewer } 4 \text { regarding our choice of methodology, } \\
\text { we want to clarify the following: The present study follows a } \\
\text { qualitative research methodology that falls into the } \\
\text { interpretivist tradition of social science research. As Crotty } \\
\text { (1998) argues, interpretivism is 'an ontology in which social } \\
\text { reality is regarded as the product of processes by which social } \\
\text { actors together negotiate the meanings for actions and } \\
\text { situations' (Crotty, 1998: 11). Nowadays, interpretive social } \\
\text { research represents an established research paradigm and, in } \\
\text { contrast with (critical) realist ontologies, which assume the } \\
\text { existence of absolute truths, acknowledges the existence of } \\
\text { multiple subjective realities and attempts to grasp these } \\
\text { realities by 'understanding the world of lived experience from } \\
\text { the point of view of those who live it' (Locke, 2003: 7). } \\
\text { Qualitative research most commonly makes a contribution to } \\
\text { scientific knowledge through inductive theory development and } \\
\text { the generation of various types of theoretical advancements } \\
\text { (Quinn-Patton, 2002). Qualitative research provides the means } \\
\text { for exploring and understanding the meaning individuals or } \\
\text { groups ascribe to social or human problems. Data analysis } \\
\text { inductively builds from particular to general themes and } \\
\text { requires from the researcher to make interpretations of the }\end{array}$ \\
\hline
\end{tabular}




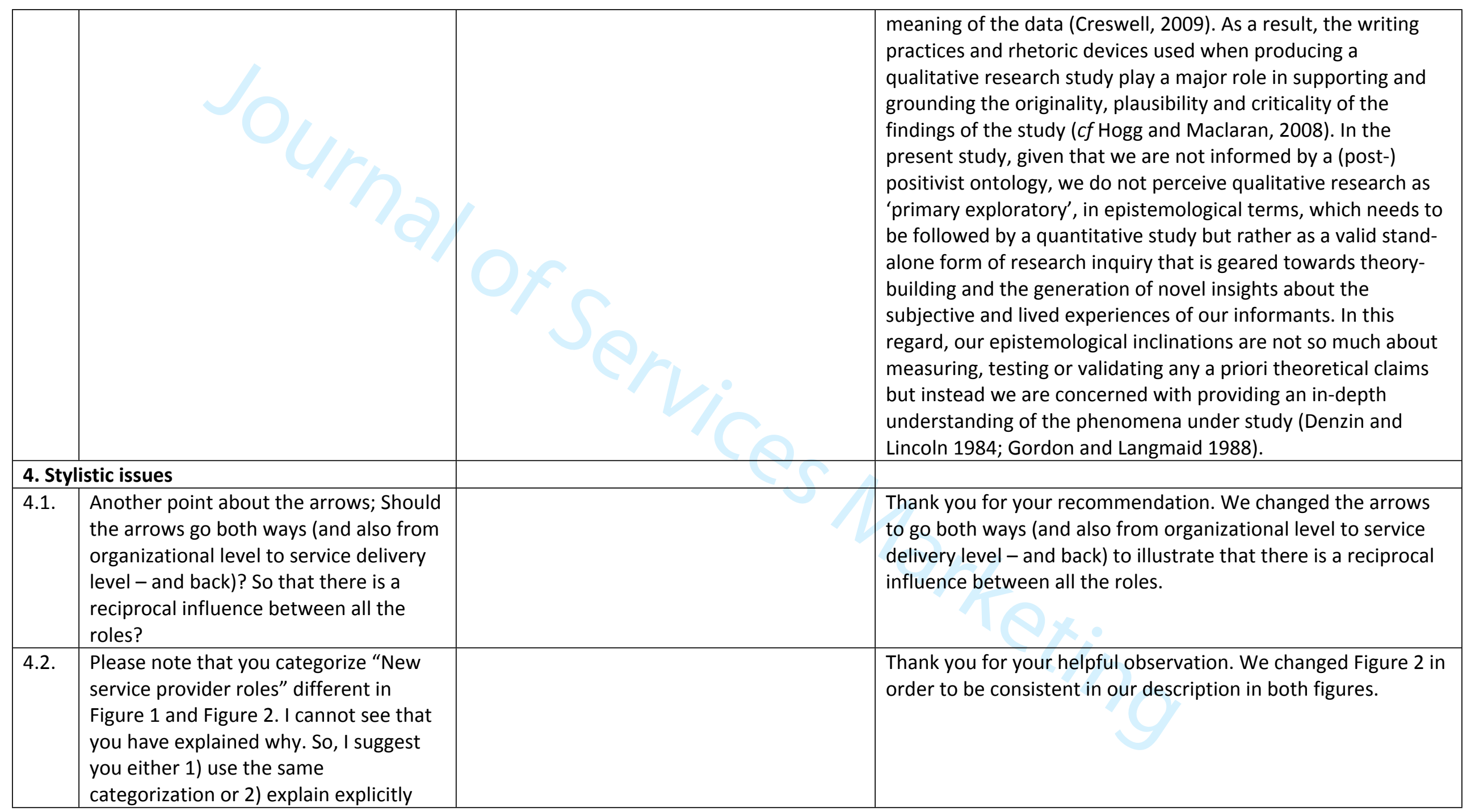




\begin{tabular}{|c|c|c|c|}
\hline & $\begin{array}{l}\text { why you use a different categorization } \\
\text { in Figure } 2 \text { (compared to in Figure 1). }\end{array}$ & & \\
\hline 4.3. & $\begin{array}{l}\text { I am wondering a bit about the word } \\
\text { "evidence". Does your results provide } \\
\text { empirical evidence - or are empirical } \\
\text { results or empirical indications more } \\
\text { correct? I have a feeling that the word } \\
\text { "evidence" is a bit too strong. }\end{array}$ & 0 & $\begin{array}{l}\text { Thank you for your observation. We changed to "we illustrate } \\
\text { empirically" across the manuscript. }\end{array}$ \\
\hline 4.4 . & $\begin{array}{l}\text { Page 4, line 14: Should "Service } \\
\text { interactions can be therefore described } \\
\text { as" changed to "Service interactions can } \\
\text { therefore be described as"? }\end{array}$ & & $\begin{array}{l}\text { Thank you for your suggestion. We corrected the sentence } \\
\text { accordingly. }\end{array}$ \\
\hline 4.5. & $\begin{array}{l}\text { Figure } 2 \text { is presented at the end of the } \\
\text { Findings chapter. I suggest you include } \\
\text { one or two sentences before Figure } 2 \\
\text { saying that Figure } 2 \text { illustrate } \\
\text { /summarize the different activities of } \\
\text { the roles........ I think this will improve } \\
\text { readability/flow of the story. }\end{array}$ & & $\begin{array}{l}\text { Thank you for your suggestion. We included the following } \\
\text { sentence: "Figure } 2 \text { summarizes the range of activities for each } \\
\text { one of the new service provider roles." }\end{array}$ \\
\hline 4.6. & $\begin{array}{l}\text { Page 3, line } 29: \text { To avoid any } \\
\text { misunderstandings you may rewrite } \\
\text { from "...identify relationships between } \\
\text { them." to "...identify relationships } \\
\text { between these roles." }\end{array}$ & & $\begin{array}{l}\text { Thank you for your suggestion. We corrected the sentence } \\
\text { accordingly. }\end{array}$ \\
\hline
\end{tabular}


Bowen, 2016;Giebelhausenet

enabler, differentiator

sense-giver

innovator, coordinator

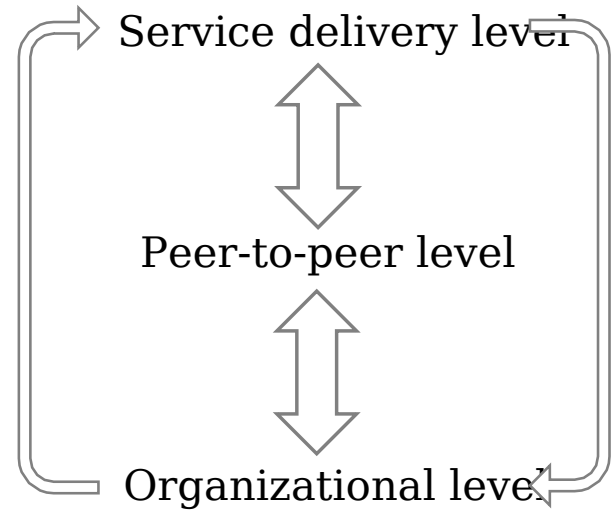

Level of impact al., 2014; Larivièreet al., 2017; Lohndorf and

Diamantios, 2014;Wünderlich et al., 2013

Ashforthet al., 2008; Pratt, 2000

Breidbachet al., 2016; Bowen, 2016; Cadwalladeret al., 2010; Larivièreet al., 2017; Ordanini and Parasuraman, 2011

New service provider roles

\section{Examples}


enabler, differentiator

sense-giver

Innovator, coordinator

New service provider roles
Enable all parties to perform well, evaluate and communicate information, ensure that technology is not a communication barrier, decide which information to reveal/conceal, assess consumers' 'technology readiness'

Advice others about how to use technology, provide answers about appropriate use

Leverage insider knowledge to identify opportunities, have a clinical input in the development of service innovations, integrate resources, manage multiple actors

\section{Range of activities}

